\title{
Radical Space and Resistance Movement in Maisuma, Srinagar
}

\author{
Waseem Ahmad Sofi ${ }^{1}$ and Ankur Dogra ${ }^{2}$ \\ ${ }^{1}$ Assistant Professor, Department of Political Science, ${ }^{2}$ Assistant Professor, Department of Geography \\ ${ }^{1 \& 2}$ Government Degree College, Gool, Jammu and Kashmir, India \\ E-Mail: sofiwaseemalig23@gmail.com, ankursainiki@gmail.com
}

\begin{abstract}
The paper generally deals with place-making of Maisuma (a densely populated town in Srinagar, J\&K) with its own and erstwhile Kashmir political discourse. There was visible rise of modern form of Islam unmatched with its SuiGeneris (Kashmiriyat, a culture which unlikely superior and absorbed every religion) was completely faded. In last three and half decades, the process of radicalization and separate political movements shaped and re-shaped politics of Kashmir. At the same time, Maisuma remained a symbolic and iconic space of resistance movement in Kashmir. For that reason, an attempt has been made to answer the following critical questions- Is Maisuma a radical space? How Maisuma is related to idea of separate politics in whole of Kashmir? Finally, the paper concludes with an argument that the politics of space in Maisuma made it as a terrain of resistance for most of the leaders in Kashmir. The contemporary Maisuma is a symbolic place of resistance politics for leaders of both mainstream and separatists.
\end{abstract}

Keywords: Kashmiriyat, Maisuma, Political, Geography, Space, Resistance and Politics

\section{INTRODUCTION}

The emergence of Maisuma as a radical space has geohistorical reasons. The centrality of its location within Srinagar, the summer capital of Jammu and Kashmir and dominated by people engaged in low menial jobs in congested densely populated. On the contrary, the other parts within the urban city Srinagar are allocated with middle and upper middle classes. So, probability of Maisum in contrast to other peripheral areas of becoming radical space was inevitable under the influence and idea of politics of Separatism, since the beginning of Partition of British Indian Empire. The paper is divided into many sections and after beginning with the introduction (in Section I); the paper is structures as follows. In Section II, the main objectives of the literature review has been taken. The research is primarily focused on mapping the historical and geo-political discourse through narratives of residents and local media narratives and also lensed from the Indian nationalist Media narratives. In order to make the research sound both primary and secondary sources of data were taken which were briefly discussed in the Section III of the paper. The paper is based upon a radical space, which has dynamic, dialectical and symbiotic relationship between radical culture and the sites in which it operated. Citing the complex interactions between radicalism, space and power in Maisum, report is taken under the auspices of a spatial approach that are briefly discussed in the Section IV. Section $\mathrm{V}$ of the paper briefly discusses the history and geography of Maisuma. The politics of space in Maisuma and its close proximity to (Lal Chowk or Red Square, Srinagar) made it as a terrain of resistance for most of the leaders in Kashmir. The evident inevitably forged Maisuma a symbolic place of resistance politics for leaders of both mainstream and separatists. Section VI of the paper therefore examines how Maisuma became an iconic space of resistance movement in Kashmir. The next Section VII discusses the political discourse and radical movements in contemporary Maisuma. The major findings and suggestions that have been drawn in the study were discussed in the Section VIII of the paper. Finally, the paper has been concluded in Section IX with an argument that Kashmir conflict is most likely, driven by 'Deep State terrorism' carried out, on the behalf of both Pakistan and the Indian State separately for their political interest and nationstate expansion.

\section{REVIEW OF LITERATURE}

This report initially deals with the historical background of Maisuma or Maisum, a densely and congested populated neighbourhood downtown area near Srinagar. In broader terms, its main objectives are

1. Seven decades of geo-historical political discourse in Maisuma, profoundly associated within the Kashmir idea of separatists politics.

2. How Maisuma became the Iconic space of Resistance, especially after the emergence of Muslim united front which acted as a fillip to already existing politics of separateness.

3. How the people in terrain of resistance (Maisuma) faces everyday challenges over the consecutive fourth generation of resistance politics.

The seven decades of geo-historical political discourse is mainly extracted from local media and local narratives through various newspapers like Life Kashmir, Rising Kashmir, Greater Kashmir and The Caravan. The political discourse is basically the interpretations are on the basis of relevant and related articles within the framework of time and space related to field.

\section{RESEARCH METHODOLOGY AND SOURCES OF DATA}

The research is primarily focused on mapping the historical and geo-political discourse through narratives of residents 
and local media narratives and also lensed from the Indian nationalist Media narratives. The centre focus is on the lived and everyday experience of the residents and shopkeepers livability, in never ending place of blood and memory. The main focus is on highlighting the politics of space and nuances of political approaches in a place towards general masses. The paper is generally based upon the methods of qualitative research, as the nature of report and questions (Interview) framework.

Both Primary and Secondary data were used in the study. Primary data is all based upon the in-depth interviews with residents and shopkeepers to closely comply with the objectives of the paper. Few informal discussions with known ones also helped in reinforcing the perspective about the report. Secondary data is mainly drawn from various newspaper articles, books, Internet and YouTube to make a better understanding of literature review and theoretical understanding in the paper.

\section{RADICAL SPACES AND POLITICS OF RESISTANCE}

The paper is based upon a radical space, which has dynamic, dialectical and symbiotic relationship between radical culture and the sites in which it operated. Citing the complex interactions between radicalism, space and power in Maisum, report is taken under the auspices of a spatial approach, the histories (and historiographies) of radicalism, identity, the public sphere, performance, justice, protest, memory, publishing. If indeed Radical Spaces is the spatial turn in action (more on which later), it demonstrates that more work is needed to integrate such analyses into the canon of social and cultural history. The political theorist has long term engagement in dealing crucially between the space and democracy, space has been always undertheorized under political theories. Margaret Kohn argues that spatial configurations serve as powerful social forces that can naturalize social divisions or call them into question.

Margaret Kohn makes the case that space is an important mechanism of social power. With Pierre Bourdieu, Michel Foucault, and Henri Lefebvre (among others), she agrees that space can function to reproduce and to reinforce relations of domination. She also emphasizes space in terms of transformative political role, enabling and encouraging the oppressed to challenge and to change social relations of power. The Radical Space helps raise such questions is one of its principal contributions to ongoing debates about democratic politics and popular resistance to power. Research on politics of resistance within the field of geographic studies has, in the main, concentrated on the collective, conscious, and organized responses of microregions. Analysis of resistance has tended to focus on reactions by societies against ruling class. Largely inspired by labour process theory, such studies draw on a 'Newtonian' conceptualization of resistance as the outcome of structural relations of antagonism between ruling and general mass (Knights and McCabe 2000). As Fleming (2002: 194) comments, resistance has rested upon 'the nomenclature of dialectics, true interests and overt antagonism. While research has drawn attention to the ways in which general mass dissent and resistance is manifest in organizations, the definition of resistance used results in the neglect of other forms of more subtle or hidden disruption. Consequently, some forms of resistance may remain under searched and certain groups of actors neglected in analysis. Moreover, such studies fail to capture the complexities and nuances of resistance at the level of the individual, and the motivations of individuals to resist.

\section{GEOGRAPHY AND BRIEF HISTORY OF MAISUMA}

The name 'Maisum' comes for its Sanskrit name 'Makshikaswamin'. Historically, Maisuma covers the entire area that is more or less an island that forms the center of present day city of Srinagar, summer capital of Jammu and Kashmir. In other words, historical Maisuma includes Srinagar Golf Course, Polo Ground, S.P and Women's college, Bar Bar Shah, entire neighborhood of Amira Kadal including old Court Complexes, Tyndale Biscoe School, Abi Guzar and entire Residency Road all the way up to Door Darshan center. In contemporary times Maisuma falls under the Amira kadal constituency. The geographical landscape of Maisuma or Maisum impacted largely under the seven decades of rigorous political discourse of Kashmir. Currently, Maisuma falls under the Amira Kadal constituency, used to be a favorite site for both mainstream and separatist politics under various Kashmiri leadership. People in Maisum used to be very much fascinated about the local Kashmiri leaders. The tug of war between the people of two probable wining factions was very common phenomena. The heated political debates intensely was dominated shows the love of people towards politic in densely neighborhood downtown of Srinagar.

Even before nation states of India and Pakistan came into existence the people of Maisuma and surroundings had mobilized themselves against subordination, injustices and oppression by ruling class. In 1931 an attempt was made by young Muslims to organize a deputation to Maharaja Hari Singh, but it ended in a riot where 21 persons were open fired by police of the then ruler. Maisum, then as now a lower menial working class, a densely populated neighborhood in the heart of Srinagar emerged as the centre of support to Sheikh Mohammed Abdullah's campaign to free people largely Muslims of Jammu and Kashmir from Autocratic Dogra's empire rule. In 1940's became increasingly clear that Autocratic regime could not reform to the extent demanded by increasing mobilization of the nascent political conscious population of Maisuma particular and erstwhile Srinagar. All Jammu and Kashmir Muslim was the first political party formed by Sheikh Abdullah to direct growing movements for social and political change. In 1938, Muslim conference internal debate took place and redefined the politics to end 
communalism, and invited all Hindus and Sikhs who believe in freedom of country from the handcuffs of Autocratic rule. In1939, the first political party Muslim conference renamed as All Jammu and Kashmir National Conference when 173 delegates voted in favor of JKNC out of total 176.

National Conference strategically, from its very inception steeply in distinctly Muslim ethos, shaped above all Kashmir culture and traditions. In 1947, NC proved to be remarkably dynamic agent of political mobilization and a proud shared regional patriotism rooted in Muslims youth identity with the promise of progressive social change. In 1946, Quit Kashmir Movement, Sheikh Abdullah during a public speech said: "Time has come to tear up the treaty of Amritsar....Sovereignty is not the birth right of Maharaja Hari Singh. Quit Kashmir is not a question of revolt. It is a matter of rights". This conceptions shows as Indians were demonstrating against the British Empire, equally to some extent Kashmir nascent popular political mobilizations were fighting freedom from Autocratic Dogra Empire. As a result, on 17 March 1948 Sheikh Abdullah who was politically leading the mobilizations became the Prime minister of Jammu and Kashmir.

After the Partition of British India Empire into two dominions India and Pakistan, soon after Tribal raids from Mirpur now in Pakistan compelled Maharaja Hari Singh the then ruler of princely state Jammu and Kashmir to access with India to protect Jammu and Kashmir of becoming frontier zone between India and Pakistan. When Maharaja finally accepted to Accession the then Governor General of British empire, Mountbatten wrote, "In the view of the extraordinary situation you have referred to, my government accepts Kashmir accession to Indian dominion with a proviso that the issue of accession of state, where accession is a matter of controversy, be sorted out according to wishes of people of the state". In accordance to above statement, Sheikh Abdullah who was popular leader among the masses of Kashmir led to resulted in incorporation of Article 370 in Indian 33 Constitution and the beginning of electorate process in Kashmir. Sheikh Abdullah, in his first speech of 1951 kept three options for the people of Kashmir as: "Continued accession to India, Accession to Pakistan and not joining either of the state and have a healthy and friendly relation". Finally on 6th of February 1952 the accession to India is finally ratified. On the part of India it was consider a proud moment and the then Indian leaders were grateful to Sheikh Abdullah for his help at such a crucial juncture for the people of Jammu and Kashmir. The results of such complications in relation to Maisum are discussed in next topic 'the process of radical movements'.

\section{MAISUMA AS AN ICONIC SPACE OF RESISTANCE MOVEMENT IN KASHMIR}

The politics of space in Maisuma and its close proximity to (Lal Chowk or Red Square, Srinagar) made it as a terrain of resistance for most of the leaders in Kashmir. The evident inevitably forged Maisuma a symbolic place of resistance politics for leaders of both mainstream and separatists. It is a congested settlement and densely populated locality near Srinagar dramatized by the wining wave of Muslim United Front (MUF) in 1987 democratic elections of Jammu and Kashmir state. Islamic Students League (ISL) being the youth street voice, dominated by youths of Maisuma and erstwhile Kashmir played a valuable contribution towards making Muslim United Front (MUF) a force to be reckoned but soon after such events of rigging of election resulted in outbreak of militancy or armed rebellion. Soon After election results, Mohammad Yusuf Shah and other MUF candidates and ISL youth leaders were arrested and put behind gallows. Mohammad Yusuf Shah used to maintain highest decorum among other MUF leaders. He got released from jail on the orders of Jammu and Kashmir High Court order and took back its position as a chief of Jammat-ulIslam in Kashmir.

Farooq Abdullah, now as then, was Chief Minister of state, informed Rajiv Gandhi about countering emergence of armed rebellion. The results of flawed democracy in 1987 elections were coming out be disastrous for India. On the contrary, it was ease for Pakistan and painful for common ethnic Kashmiri general mass. The elections enacted by visible huge fraud and cheat. On 20 January 1990 more than 100000 Kashmir Pandits were forced to flee from Kashmir due to outbreak of militancy or armed rebellion against the state. It was the Governor Jagmohan who created a panic like situation in the Valley and facilitated the exodus of Kashmiri Pandits by providing them with transport vehicles to move out of the Valley. This was the monumental error on the part of Governor Jagmohan. He may have had no intentions of fuelling the exodus but his mismanagement of the entire conflict will never be forgotten or forgiven. And one of the greatest tragedies about the debate revolving around the fate of Kashmiri Pandits is that the story of their pain and suffering has been communalized beyond imagination. Instead of objectively analyzing the causes and reasons behind the ethnic cleansing of Kashmiri Pandits following the outbreak of insurgency in the Valley, secessionists and nationalists, both have tried to tell only that part of the conflict which has suited their political interests.

\section{POLITICAL DISCOURSE AND THE RADICAL MOVEMENTS IN CONTEMPORARY MAISUMA}

Maisuma has become symbolically an Iconic representation of the whole of Kashmir. It is possible to find a way of dealing with cultural difference without falling into complex trap of clashes, armed rebellion and tension? At the deep level of sense, history is a medium of dealing with identity, togetherness and difference. Every meaning in the history especially the meaning related to human subjectivity is a 'construction' or an 'invention'. Identity loses its relationship to experiences and to everyday reality of being. Initially, Kashmir was hub of the strong culture bindings and affections. The political space of power structure should 
have destiny which rise above the egos and personal likes and dislikes to a common shared solution for Kashmir. There is always a bitterly rivalry between India and Pakistan, amidst conflicted Kashmir since partition resulted in three wars, jolt felt by millions of people across these two nations. Since 1989, according to Jammu and Kashmir state statistics, one hundred thousand people have been killed, 135657 people particularly youth have been arrested, 22819widowed, 10283raped and thousands of disappeared. The magnitude of such an exodus killings came out of armed rebellions by separatism and deep state terrorism with inhuman and draconian laws like PSA, TADA, AFSPA, NSA and POTA acts.

Since 2008, various issues have evolved like contentious Amarnath land row issue initiated by Masrat Alam a pioneer of 2010 uprising in Kashmir also named as resistance poster boy by local media. The issue reinforced the polarization of Muslims and Hindus in whole of the state. For the first time in history of Jammu and Kashmir that BJP got 11 seats from the Jammu division. In 2014, fear of BJP trying to inroads in Kashmir triggered a chain reaction that led to participation of $65 \%$ of voters in state benefited both BJP in Jammu with 25 seats against PDP in Kashmir with 28 seats, later both made coalition government on agenda of alliance. And since then, the intensity of civil resistance movements has drastically increased. The other major unrest evolved out of Shopain rape and murder, 2010 summer turmoil and the most recent 2016 killing of Hizb militant Burhan Wani. The prolonged cycles of unrest have affected the development scenario in Kashmir. It is not acted as a barrier to private investment but created hurdles in forging basic infrastructure for delivery of public services. 2016 uprising in Kashmir, cause tremendous miseries, loss of life, complete halt of economic activities coupled with loss of property worth Crore of rupees.

A Kashmiri friend in an informal talk told: "The public spaces till 2008-2010 were mainly urban centric and young boys have taken these spaces and commandeering with its own rhythm and momentum. In uprising of unrest in 2016 after the death of Hizb-ul-Mujahideen militant Burhan Wani there is a paradigm shift now, even rural areas of Kashmir are largely participating in their own momentum further shrinking the mainstream politics in Kashmir previously managed by rural places".

The post uprising 2008 have almost changed the Maisum landscape by perpetual long spells of protest and agitation. The milkman made deliveries 12 at night. People are used to dump stock of rations for months. As one shopkeeper told, "yeh hamari purani addat hai (This is our old habit)". In other words, while the armed struggle may have waned, many of the (war-time) habits of Kashmiris, what a Pierre Bourdieu has termed 'habitus' continue to be the part of contemporary societies in Kashmir. A young anonymous told, "Now Kashmir is not a religious struggle. Those Kashmiris who belief it is a Religious struggle are not Kashmiris and could be the enemy of Kashmir".
A young anonymous in an informal conversation said, "The core issue in Kashmir since its accession to India after 1947 is Autonomy. Autonomy in his words relates to two aspects of identity in Kashmir. One is culture identity, sui-generis in nature as its natural beauty and belongs to both Hindu and Muslims Kashmiris and the other is bulk political identity which has always been separated from the main stream political identity of India. The culture identity which is and always has been Sui-Generis in its nature and in the process manifests autonomy for itself whereas bulk political identity which demands development and in turn grievances regarding the applications of the development machinery again manifests itself with autonomy". "Agitational terrorists" a technical term coined specifically for the Kashmiri protesters is also deployed to subsume the Kashmiri resistance movement within the spectre of global terrorism. Kashmiris simply want Independence from India. The famous slogans that continues to ring in the valley is 'Tchyeen ke lain gey Azadi'- We will snatch our freedom (from India). These protests came on the heels of the mass uprising that has been ongoing since the killing of Burhan Wani in July last year. A local young told when I asked him about Burhan Wani a Hizb-ul-Mujahideen militant: "He has become the face of indigenous Kashmiri struggle against India in no time. His killing motivated Kashmiri people of all ages and genders to take to the streets and the government responded with lethal force. Maisuma was put under a three-month curfew, media was censored and mobile phone and Internet services were curtailed".

In an article (captive city), Wasim Bhat said, "How many gun barrels stare us? Enough to keep us anxious and edgy, always looking over our shoulders. We are the children of war that has no feeling of doubt or hesitation with regard to the morality or propriety of a course of action. The war that moves in billion synapses of our brain, releasing chemicals that makes us anxious and way, tiring us making us old. Catching us unaware, it has captured the rhythms of our being. The birds I saw in my childhood are no more. Songs are forbidden in this forgotten city. The snow has not yet covered the mountains gorges, the crevasses are frenzy of rock and gravel. The dogs bark incessantly throughout the night, lost in the streets and dark alleys. The cars are blur and pedestrians wary. Olive green and irritated, the military vehicles snarl and rumble through narrow potholed roads, blaring horns and flashing headlights. They are overlords of this earth, plumed birds have fled. The constant din keeps the awake, in enduring captivity". By November 2016, close to 100 Kashmiris had been killed and more than 15,000 injured at the hands of Indian forces and political engagements are more worsening. The victims of what came to be known as the world's first "mass blindings" were also among the injured. Indian troop's use of pellet guns left more than 6,000 people injured in one or both eyes in recent protests in Maisum. Kashmir continues to be volatile even after hundreds of killings in the next year and oppressive measures against dissenting civilians - who found prominent space after the killing of Wani. It was once said that Wani will be more influential from his grave than 
alive. Two years after the popular rebel commander Burhan Wani was killed by Indian government forces in the disputed Kashmir region, the Kashmir Valley has changed in many ways - from the rise in violence to the growing instability of the political system. Following the break-up of the BJP and PDP coalition government, the State came under Governor's rule. The alliance between the two parties was based on compromises on both sides. The agenda of alliance, which was conceptualized by Ram Madhav of the BJP and Haseeb Drabu of the PDP, held together the two poles for quite some time. However, the coalition fell apart under the weight of its own contradictions and the PDP became a victim of the BJP's political expediency. Today, the future of the PDP in the State looks bleak. Twentynineteen (2019) is an important year in India. It is a year of elections. Besides the general elections to the Lok Sabha and the Rajya Sabha, six assembly elections are set to be conducted by the Election Commission of India this year. Hope these elections will be conducted in a democratic manner and will create a permanent peace and stability in the state.

\section{FINDINGS AND CONCLUSION}

The following are the Major Findings and suggestions can be drawn

1. Kashmir conflict is most likely, driven by 'Deep State terrorism' carried out, on the behalf of both Pakistan and the Indian State separately for their political interest and nation-state expansion. India, on the other hand can be categorized as 'deep state' within the geographical landscape of Kashmir in contrast to Pakistan, which is 'deep state' in its entirety, manipulates region of its being advantageous. This in turn has transformed the land of peaceful Sufis and saints into an endless space of armed rebellion and place of blood-shed in the memories of the erstwhile inhabitants.

2. The mantle of resistance has been picked up by third generation of Kashmir's, who seems to have no fear of persecution. The new third generation is actively connected to social media as a new form of modern resistance.

3. The bureaucrats and politicians at the centre do not have the direct interaction with the regions; their interest is only to have reliable power base in periphery. An old practice of Britishers, which never saw much advantage in direct control in Himalayan Mountains. Equally, the local elites in Kashmir exaggerate reports of their influence over the people in order to gain maximum advantage from the centre. However, this long old practiced has led to mass killings and atrocities to innocent general mass of ethnic Kashmir. Both of these stake holders wield power and exercise authority over innocents. Now the question arises: "Is there is any system or policy-making that can check balance these power relations?"

4. Over the last 20 years Muslims Kashmiris and Hindu Kashmiris are not only apart in physicality but also tell different stories about this separation in their own plot, conspiracy theories etc. Juxtaposed with stories about past harmony or conflict, they create a contested ethnic political space that has potential for unsettling dominant narratives.

5. There is little or no political will on either side (India and Pakistan) to do so; neither has a perception that might lead to a meaningful compromise. Furthermore, both are able to survive without resolving the Kashmir dispute. Finally, the world and the United Nations are, currently, not terribly interested in the dispute, except to prevent India and Pakistan from going to war.

\section{REFERENCES}

[1] Sanjay, K. (2011). Until my freedom has come: The new intifada in Kashmir. India: Penguin Books.

[2] Amrinder Singh, D \& Aditya, S. (2009). Kashmir: The Vajpayee Years. India: Harper Collins Publishers.

[3] Basharat, P. (2010). Curfew Nights. India: Random House.

[4] Tabish, F. (2008, Oct. 27). Political history of freedom struggle. Srinagar: Greater Kashmir.

[5] Abdul, B. (2016, Dec. 5). Sheikh Abdullah- A CIA profile. Srinagar: Kashmir Life.

[6] Mohammad, R, (2016, Dec. 28). A Statesman. Srinagar: Life Kashmir.

[7] Mirwaiz, K. (2016, March 24). Battleground Amira Kadal. Srinagar: Life Kashmir.

[8] We must speak up for Kashmiri Pandits, but not the way most people do! By Saif Ahmed Khan on June 2014 in Youth Ki Awaaz Directly accessed at https://www.youthkiawaaz.com/2014/06/must-speakkashmiri-pandits-way-people/ on 03 May 3, 2019

[9] Danish, N. (2015, Aug. 5). The day change Kashmir never before. Srinagar: Rising Kashmir.

[10] Altaf, H. (2016, June 25). Pandits must return to Kashmir. Srinagar: Rising Kashmir.

[11] Praveen, D. (March, 23, 2016). How Mufti Mohammad Sayeed shaped the 1987 election in Kashmir. Srinagar: The Caravan.

[12] Altaf, S. (2014, Aug. 11). Roaring, Caged and Controversial. Srinagar: Rising Kashmir.

[13] Kashmir: Two Years after Burhan Wani by Fahad Shah on 10 July 2018 in - The Diplomat. Directed accessed on 03 May 3, 2019 at https://thediplomat.com/2018/07/kashmir-2-years-after-burhan-wani/

[14] Kashmir Politics in the Shadow of Pulwama by Basharat Ali on 21 February 2019 in - The Hindu Directed accessed on 03 May 3, 2019 at https://www.thehinducentre.com/ the-arena/current-issues/ article 26328423.ece. 